\title{
Characteristics of low frequency oscillations of the atmosphere-ocean coupling
}

\author{
Randhir Singh, B Simon and P C Joshi \\ Atmospheric Sciences Division, Meteorology $\&$ Oceanography Group, Space Applications Centre (SAC), \\ ISRO, Ahmedabad 380 015, India
}

\begin{abstract}
The low frequency oscillation of latent heat flux over the tropical oceans has been studied. The NCEP reanalyzed fields of wind and humidity alongwith Reynolds SST are used to compute the instantaneous as well as monthly mean surface latent heat fluxes (LHF) for the year 1999. The procedure of LHF computation is based on bulk method. Spectral analysis shows that significant energy is contained in Madden Julian Oscillation band in the winds, SST, moisture and in the latent heat flux. The global distribution of wind, humidity, SST and LHF oscillation on the time scale of 30-50 days are analyzed. Maximum amplitude of oscillation on this time scale in all the above mentioned parameters were found over the Indian Ocean. The fluctuation of surface wind speed and moisture controls the latent heat flux on this time scale. The fluctuation of SST on this time scale does not seem to be important over most of the oceans.
\end{abstract}

\section{Introduction}

Low frequency oscillations depicting the intraseasonal variation have been studied for quite some time. The oscillations particularly during the summer monsoon season has been studied at length. Krishnamurti and Bhalme (1976), Sikka and Gadgil (1983) and Cadet (1983) have studied the low frequency variability of the monsoon, and found two main energy peaks in the 10-15 day and 30-50 day time intervals. The first two authors have used several variables including the wind and surface pressure to carry out their spectral analysis. Sikka and Gadgil (1983) used visible satellite imagery.

Some attempts have been made to find an explanation for low frequency modes over tropics. Most of these studies were focused on the Madden and Julian oscillation, i.e., a global scale eastward propagating wave. Stevens (1983) has proposed inertial instability as an energy source for these low frequency waves. Presently, an accepted theory is the so-called mobile Kelvin wave-CISK mechanism. In this framework, the heat source (mainly latent heat released) forces equatorial Kelvin waves which propagate eastward, carrying the heat source along (Lau and Peng 1987). Various composite studies of MJO have provided insight into the evolution of large-scale circulation anomalies and their relationship to anomalous convection (e.g., Knutson and Weickmann 1987; Hendon and Salby 1994). Less emphasis has been given to the structure and evolution of associated flux of latent heat. Such fluxes are of interest for mechanism of MJO (evaporationwind feed back, Emanuel 1987) and for interaction with the ocean, especially over a warm pool where the signal of convection and surface winds is the strongest. The present study aims at examining the characteristics of these oscillations in the latent heat flux.

In section 2 , we discuss the datasets used, and in section 3 , we present the methods for computation of surface flux. Monthly averaged surface fluxes are presented in section 4, while sections 5 and 6 describe the FFT analysis, and the time series analysis, and analysis of the filtered series of fluxes and other variables. The conclusions are presented in section 7 .

Keywords. NCEP (National Center for Environmental Prediction); COADS (Comprehensive Ocean Atmosphere Data Set); LHF (Surface Latent Heat Flux); MJO (Madden Julian Oscillation); FFT (Fast Fourier Transformation). 


\section{Data used}

Various oceanic and atmospheric parameters are used for the year 1999. Wind and near-sea surface specific humidity were obtained from the NCEP reanalyzed field for the above mentioned period. SST is taken from the principal ocean dataset from the weekly analyses of Reynolds and Smith (1994). To calculate the daily latent heat flux, SST data are interpolated to daily values. The daily as well as monthly surface latent heat flux obtained from ship reports of Comprehensive Ocean-Atmosphere Data Set (COADS) for the year 1999 over global oceans was used to validate the LHF computed from NCEP reanalyzed field.

\section{Methodology for LHF computation}

In the present study, we adopt the bulk parameterization formula for the computation of latent heat flux. The latent heat flux (LHF) can be computed as

$$
\mathrm{LHF}=\rho C_{d} V L\left(q_{s}-q_{a}\right),
$$

where $\rho$ is the density $\left(\mathrm{kgm}^{-3}\right)$ of the surface air computed from the equation of state, $C_{d}$ the drag coefficient, $V$ the wind speed $\left(\mathrm{ms}^{-1}\right), L$ the latent heat of evaporation $(\mathrm{KJ}), q_{s}$ the saturated specific humidity at sea surface temperature, and $q_{a}$ the near-surface specific humidity.

The saturated specific humidity, $q_{s}$ can be calculated as

$$
q_{s}=\frac{.0622 e_{s}}{p-.0378 e_{s}},
$$

where $p$ is the surface pressure. The sensitivity experiment shows that pressure is not contributing much in LHF estimation and therefore the climatological values of pressure have been used. It is to be pointed out that the calculation of fluxes are not a primary motivation of the present study. These were used only for examining the characteristics of the low frequency oscillation.

$e_{s}$ is the saturated evaporation vapour pressure. The $e_{s}$ can be evaluated based on the relation

$$
e_{s}=T_{s}^{A}+10^{B+C / T_{s}}
$$

where $T_{s}$ is the sea surface temperature, A, B and $\mathrm{C}$ are empirical constants having the values,

$$
A=-4.928, B=23.55, \text { and } C=-2937 .
$$

The latent heat of evaporation $L(\mathrm{KJ})$ is estimated by the relation

$$
L=597 \times 4180-0.6 T_{s} .
$$

For obtaining the drag coefficient $\left(C_{d}\right)$, the relation has been employed

$$
C_{d}=P+Q \tanh \left(V^{2}-4 R\right)^{1 / 2},
$$

where $V$ is the surface wind speed, $P, Q$ and $R$ are constants having the values, $P=1.165 \times 10^{-3}, Q=$ $8.00 \times 10^{-5}$, and $R=.40$.

\section{Latent heat flux $[\mathrm{LHF}]$}

LHF on daily as well as on monthly scale were computed during 1999. For assessing the quality of NCEP derived daily and monthly averages LHF, monthly averages were computed and compared with the COADS given LHF. The observation from COADS for daily time scale is very less so it is not possible to show the geographical distribution for daily time scale. Figure 1(a) shows the resulting global distribution of monthly mean LHF estimated using NCEP data for July 1999. Figure 1(b) shows the COADS given LHF for July 1999. In figure 1(b) the gaps are because there is no observation available. From figure 1(a) the relation of total LHF to ocean currents are strongly pronounced. Higher fluxes are seen in the trade wind regions with larger component in the winter hemisphere due to larger wind speeds. Along the ITCZ the wind speed is lower and, therefore fluxes are also lower. Maximum LHF occurs in the Indian Ocean mainly south of the equator and over the Arabian Sea where the magnitude is reaching up to $270 \mathrm{watt} / \mathrm{m}^{2}$. This large LHF south of equator seems to establish the humidity source for Indian summer monsoon. The moisture is transported by Somali jet towards the Indian subcontinent. Comparing with the COADS values, for monthly time scale it was found that on an average NCEP derived fluxes are overestimated by approximately $10-25$ watt $/ \mathrm{m}^{2}$ but some pockets are there in the Indian Ocean where NCEP underestimates the LHF by $20-30$ watt $/ \mathrm{m}^{2}$. For the daily time scale differences more than $35 \mathrm{watt} / \mathrm{m}^{2}$ have been noticed. The latitudinal and longitudinal variation is well produced in NCEP derived flux. Thus, basic features of monthly mean fluxes are in good qualitative agreement.

\section{Spectral analysis of flux and related variables}

Spectral analysis for each year has been used to detect the periodicity persistent in the time series. We have computed the spectrum using the following methodology:

- the annual mean and linear trend were removed from the time series 
(a)

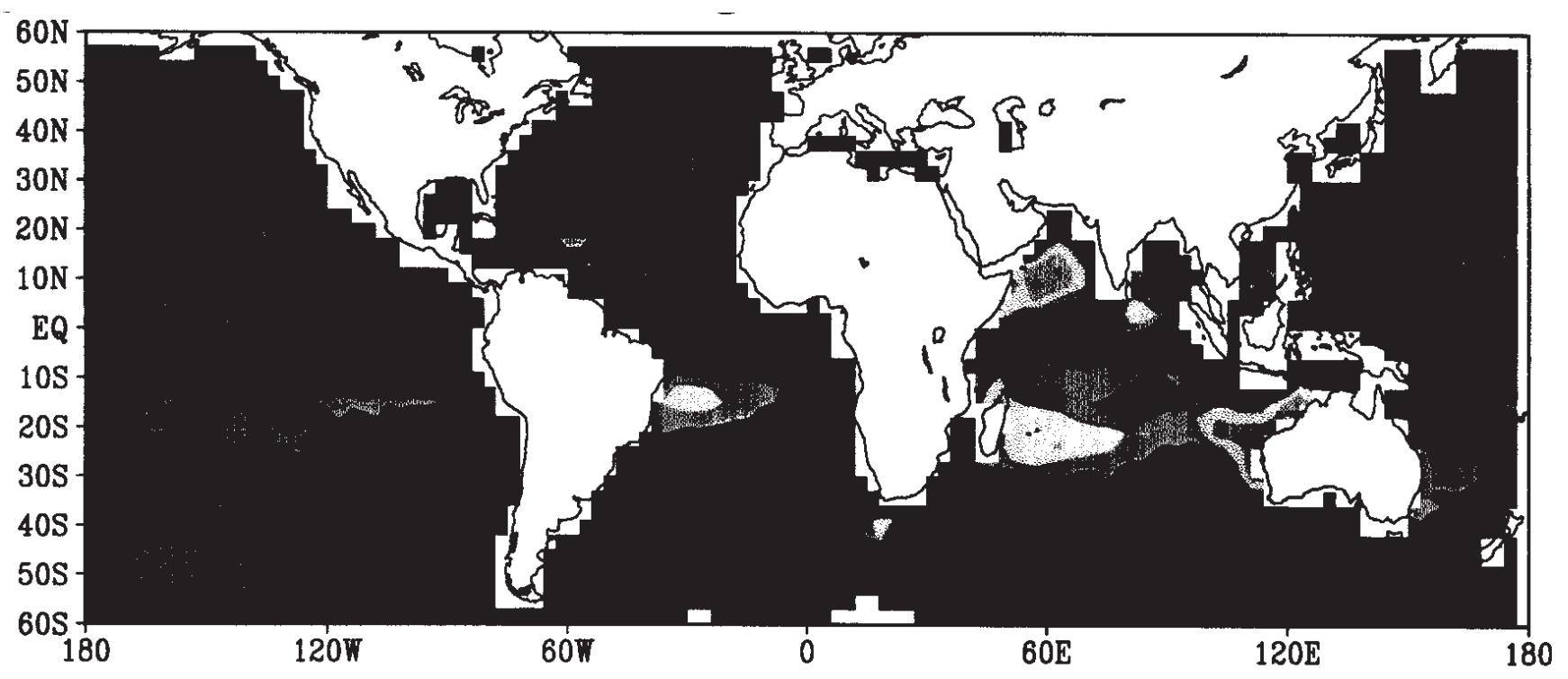

(b)

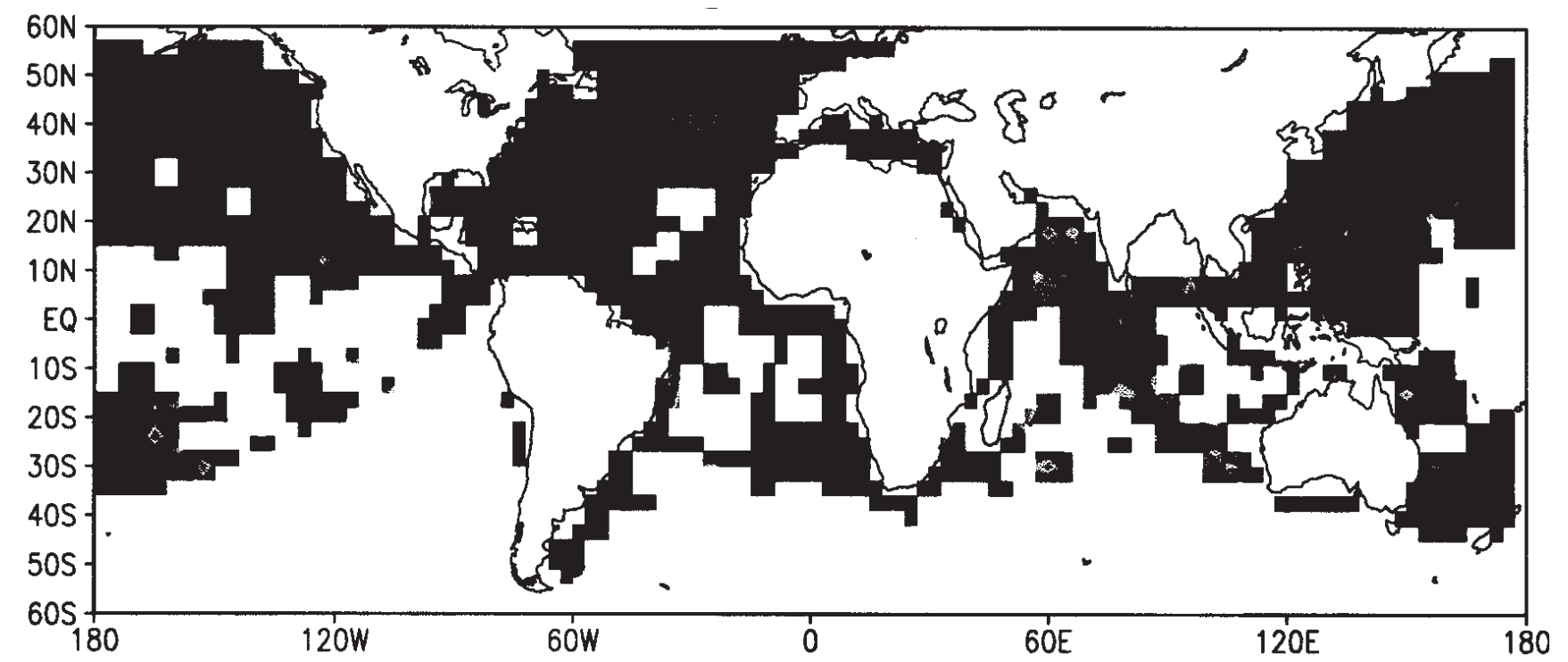

\section{$\begin{array}{llllllllllll}0 & 30 & 60 & 90 & 120 & 150 & 180 & 210 & 240 & 270 & 300 & 330\end{array}$}

Figure 1. (a) The monthly mean LHF from NCEP for July 1999. (b) The monthly mean LHF from COADS for July 1999.

- time series are tapered with a split cosine bell function (Kumar and Jain 1992)

- the tapered series are extended by adding zeros towards the end to bring the data points equal to $2^{9}=512 ; 5$ )

A Fast Fourier Transform is applied to obtain the raw spectra. To exclude the annual and semiannual oscillation we have removed the first three harmonics. After removing the first three harmonics the resulted spectra are plotted in figure 2. Figure $2(\mathrm{a}-\mathrm{d})$ shows the amplitude periodicity plot for the wind speed, SST, surface specific humidity and latent heat flux for Indian Ocean during the year 1999. The axis shows the period (days). These figures show two spectral peaks around 10-20 and 30-50 days, respectively with maximum energy in 

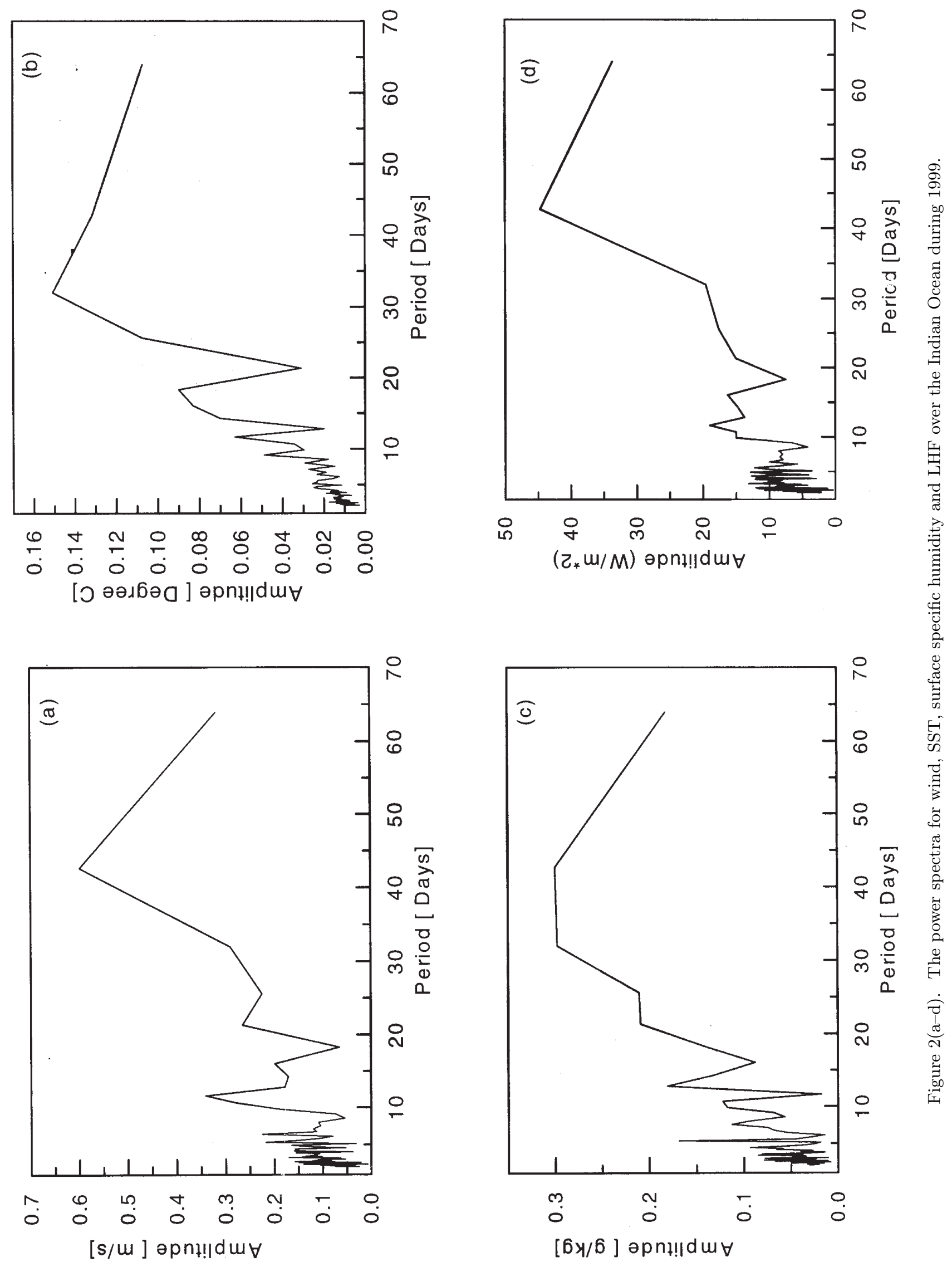

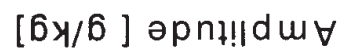




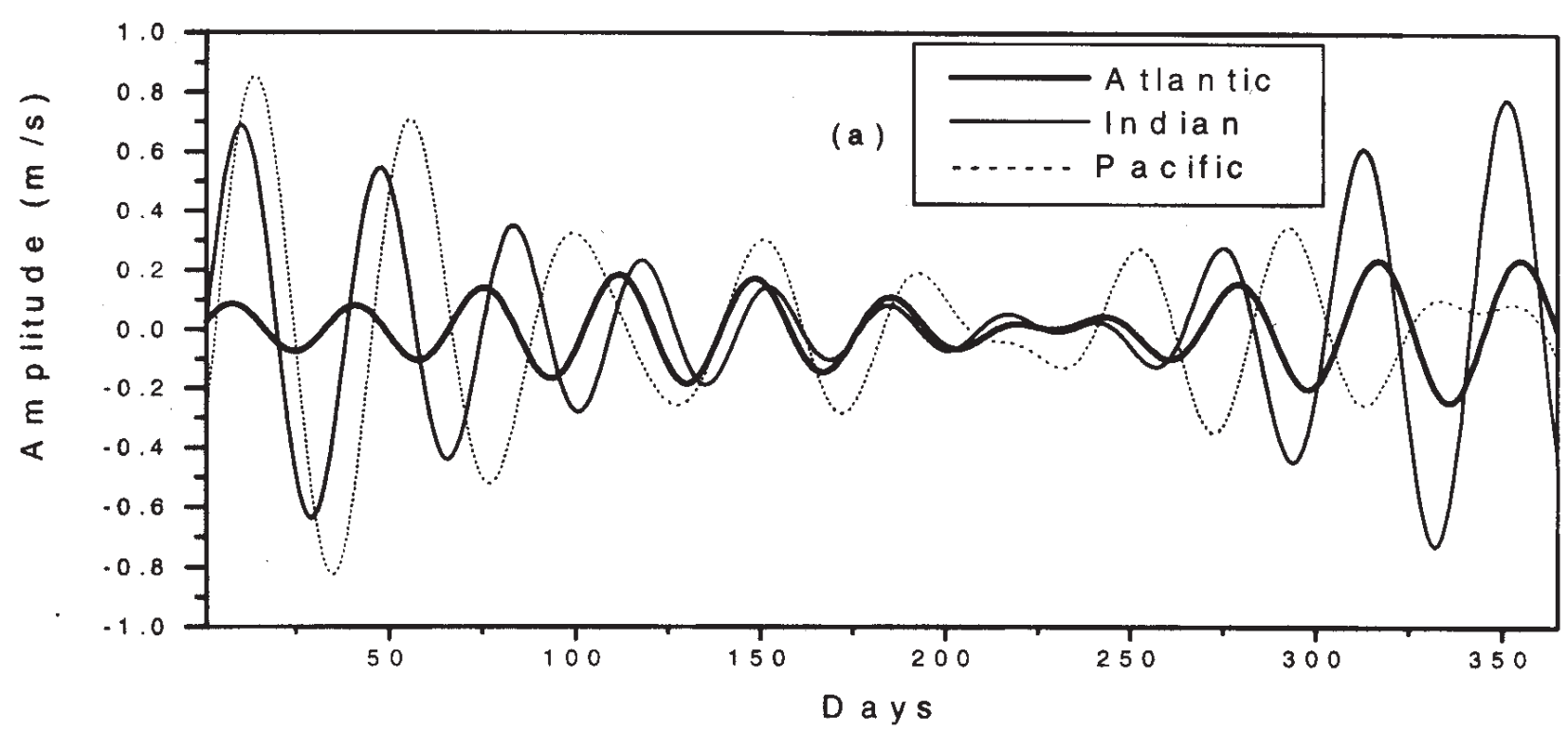

Figure 3(a). The time-filtered (30-50) series of wind over the three oceans during 1999.

the band of 30-50 days. The amplitude of these oscillations is maximum over the Indian Ocean i.e., $.6 \mathrm{~m} / \mathrm{s}, 0.1^{\circ} \mathrm{C}, 0.3 \mathrm{~g} / \mathrm{kg}$ and $45 \mathrm{watt} / \mathrm{m}^{2}$ in wind, SST, specific humidity and LHF respectively. The oscillation of the same frequency has been observed (not shown) in the Pacific and Atlantic Ocean but with amplitude less than that observed in the Indian Ocean.

From the spectral plots the maximum energy can be seen in the frequency band of 30-50 days and accordingly this particular band has been extracted and analyzed in detail. This has been done by using a fourth order Butterworth recursive filter (e.g., Murakami 1979). Given the time filtered values of any variable viz., the surface wind, the specific humidity $\left(q_{a}\right)$ and the sea surface temperature (SST), the corresponding contribution to the flux of moisture were calculated. The total flux can be considered consisting of two parts:

Total flux $=$ Flux by long term time mean variables + sum of the flux within each of individual frequency windows.

Taking the daily values of basic variables, the total flux is calculated. Similarly using the longterm time mean values of the basic variables the flux is estimated. The fluxes in the particular frequency could be obtained using these values. Our calculation thus contained the total flux, the time mean fluxes, and the low frequency (3050 day) fluxes. These fluxes were examined over the Indian Ocean $\left(0^{\circ}-10^{\circ} \mathrm{N}, 70^{\circ} \mathrm{E}-90^{\circ} \mathrm{E}\right)$, Pacific Ocean $\left(0^{\circ}-10^{\circ} \mathrm{N}, 150^{\circ} \mathrm{W}-170^{\circ} \mathrm{W}\right)$ and over Atlantic Ocean $\left(0^{\circ}-10^{\circ} \mathrm{N}, 40^{\circ} \mathrm{W}-60^{\circ} \mathrm{W}\right)$. From spectral analysis it has been observed that significant energy was con- tained in the 30-50 day mode in all the parameters. As a consequence a significant proportion of total transient flux is contributed on this time scale.

\section{Contribution of different variables on LHF}

It is also of some interest to explore which are the crucial variables contributing to the fluxes on this time scale. It should be noted here that there is strong interdependence among the basic variables also. Thus, oscillation among one or more variables on this time scale can influence the LHF. If one suppresses the variations in any one of the basic variables, some change in total flux on this time scale will result. We shall present the results of suppressing variations on the time scale of 30-50 days for one or more of the following variables:

- Surface wind.

- Sea surface temperature.

- Surface specific humidity.

If internal atmospheric forcing (such as an equatorial symmetric instability of zonal flows) was a dominant mechanism for excitation of these oscillations on this time scale, then we should expect to see a larger contribution from wind oscillations in the estimated air-sea fluxes. On the other hand, it seems unlikely that sea surface temperature fluctuations alone could contribute to these fluxes. Usually fluctuations of sea surface temperature are related to wind forcing. Being a coupled atmosphere-ocean phenomenon, a dominant contribution to the fluxes from oscillation of winds as well as the sea surface temperature is possible. 


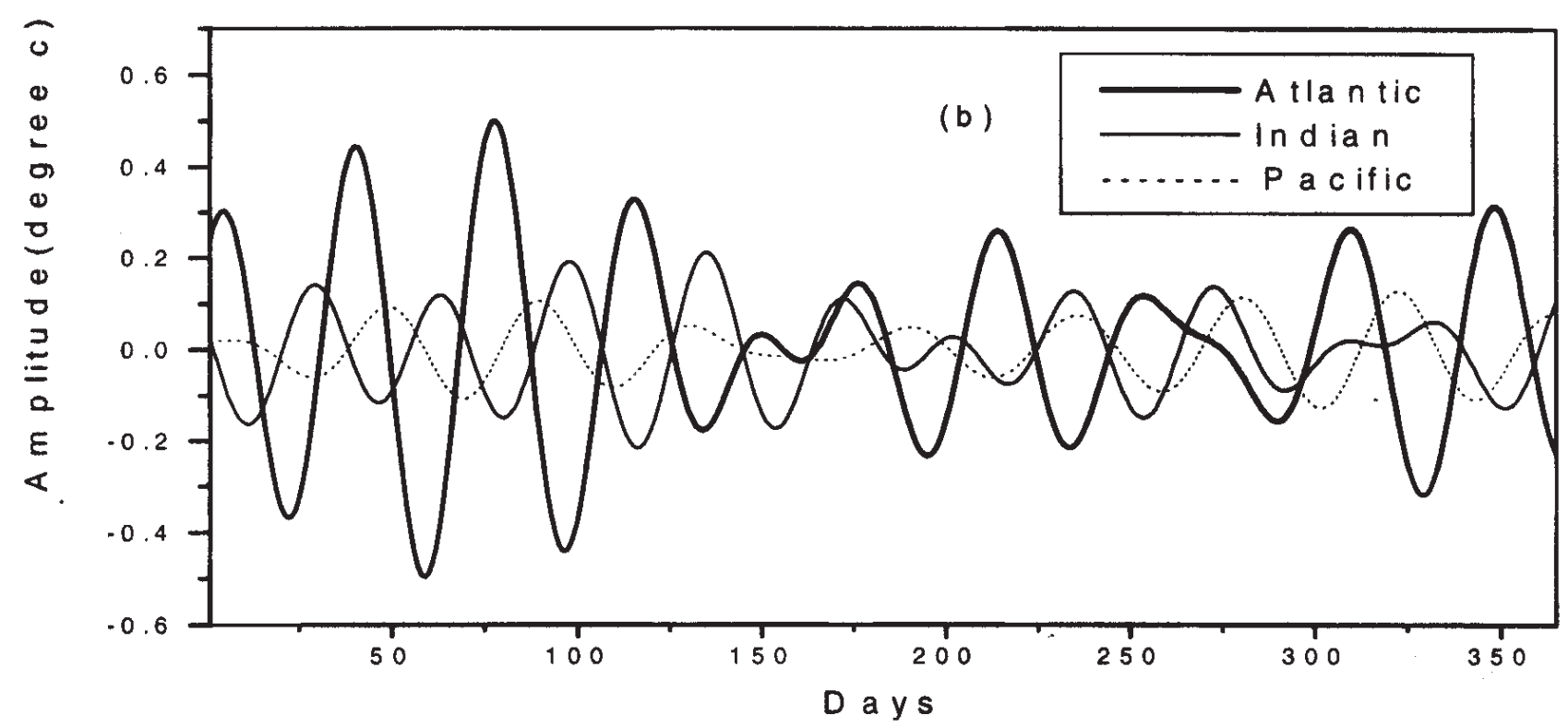

Figure 3(b). Same as figure 3(a) but for SST.

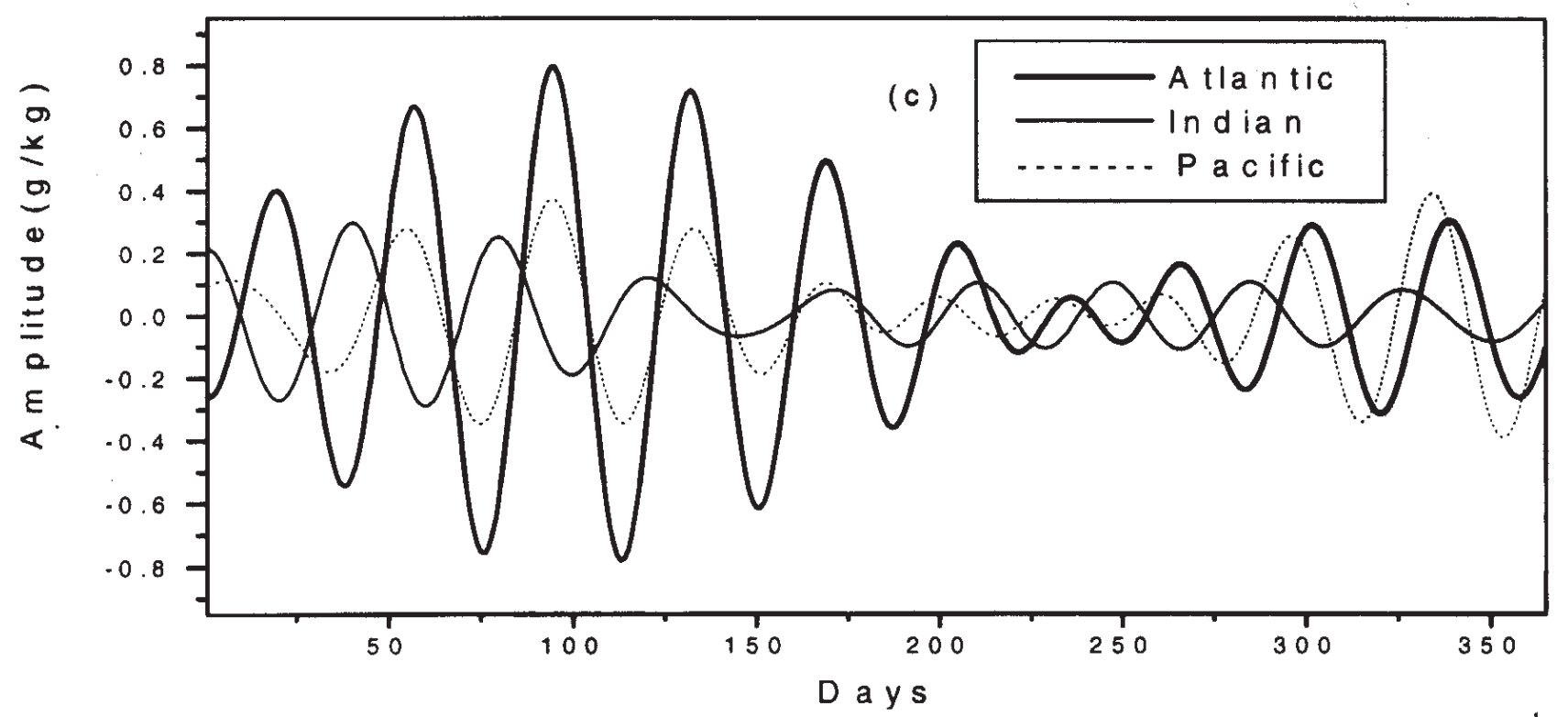

Figure 3(c). Same as figure 3(a) but for surface specific humidity.

From the time series analysis (not shown), for the Indian Ocean, we find the wind speed reaches maximum values $8 \mathrm{~m} / \mathrm{s}$ just before the onset of monsoon. The mean wind speed is about $4 \mathrm{~m} / \mathrm{s}$. The SST reaches the peak value of $30^{\circ} \mathrm{C}$ roughly 15 days prior to wind maxima from then a gradual drop in temperature occurs. The surface specific humidity maxima is coinciding with the wind maxima and also the subsequent decrease in surface specific humidity. This shows that the transport of moisture is due to high wind speed. The largest fluxes of latent heat over the Indian Ocean seem to coincide with the high wind speed. The mean value of latent heat flux is about $110 \mathrm{watt} / \mathrm{m}^{2}$. Over the Pacific Ocean the SST trend is the reverse to that of over the Indian Ocean. The SST is minimum over the Pacific Ocean when SST is maximum over the Indian Ocean. Figure 3(a) illustrates the history of the time filtered wind speed over the Atlantic, Pacific and Indian Oceans on the time scale of 30-50 days. Figure 3(b) is the same as figure 3(a) but for SST, figure 3(c) shows surface specific humidity. From figure 3(a) and (b) SST and wind speed exhibit an inverse relationship. Wind 

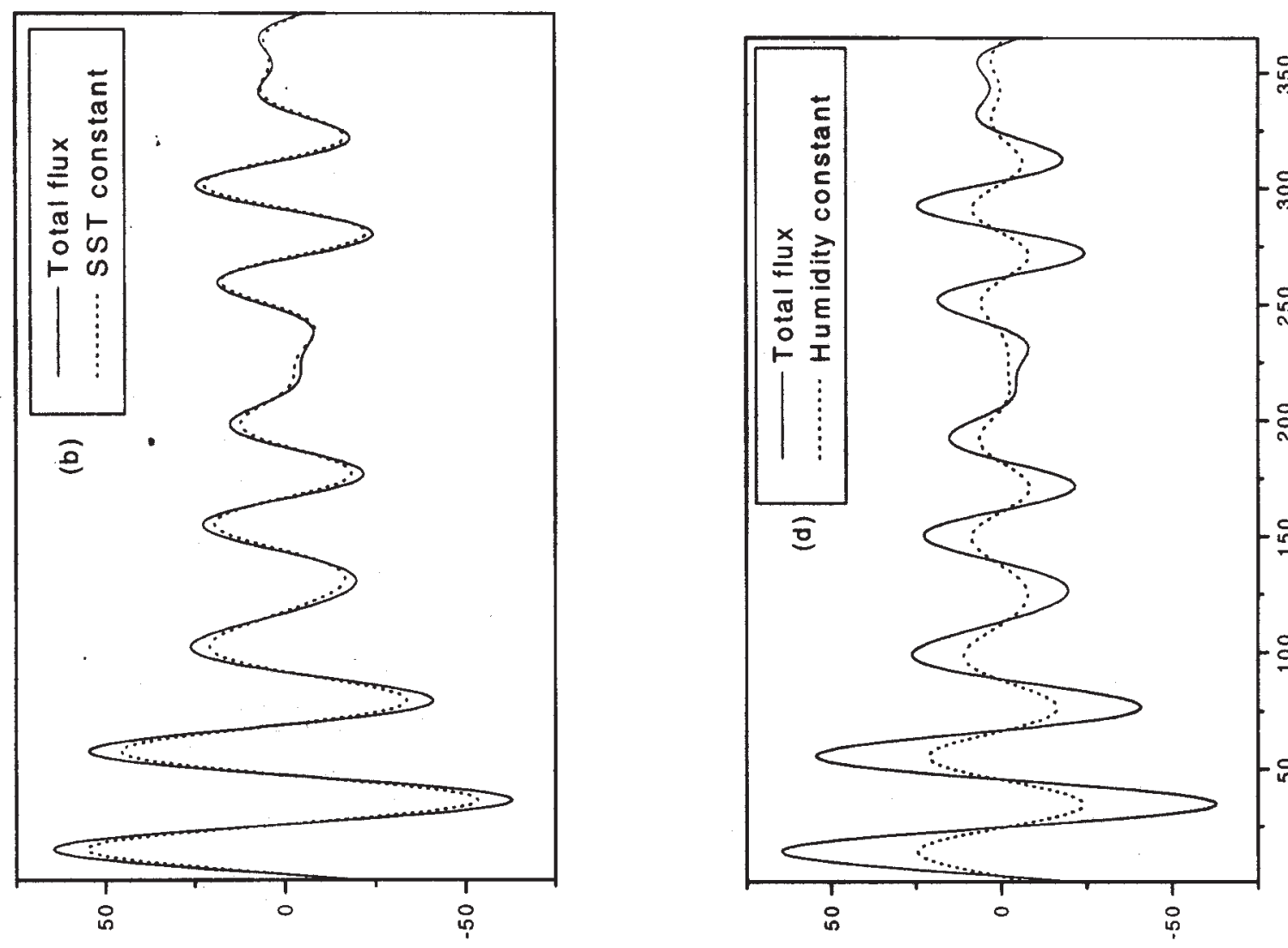

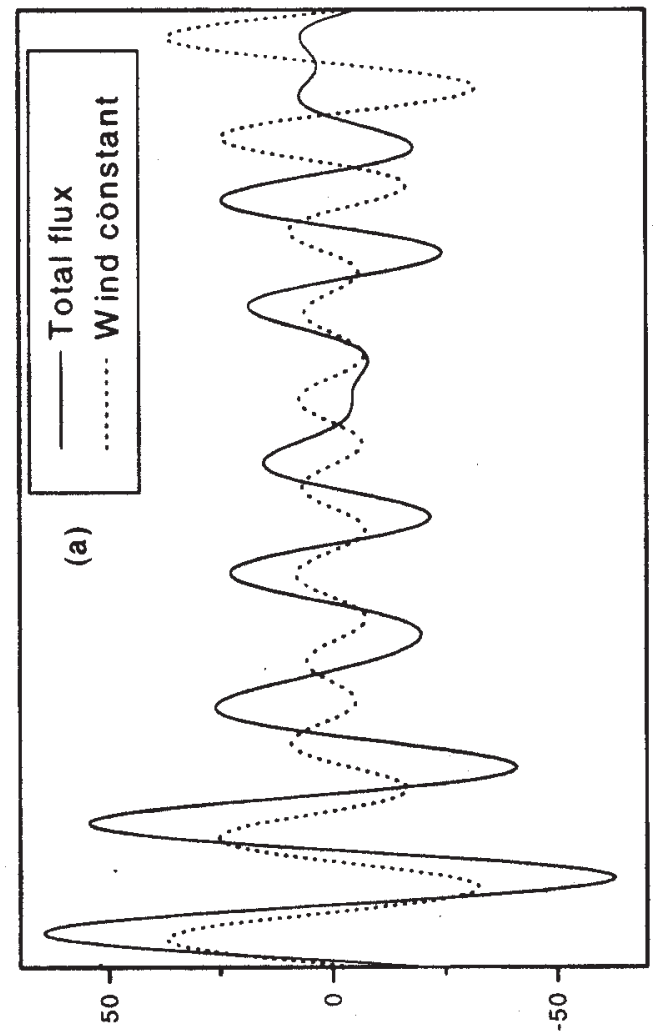

$\left(\tau_{*} m / M\right)$ әpn!!d $d u \forall$

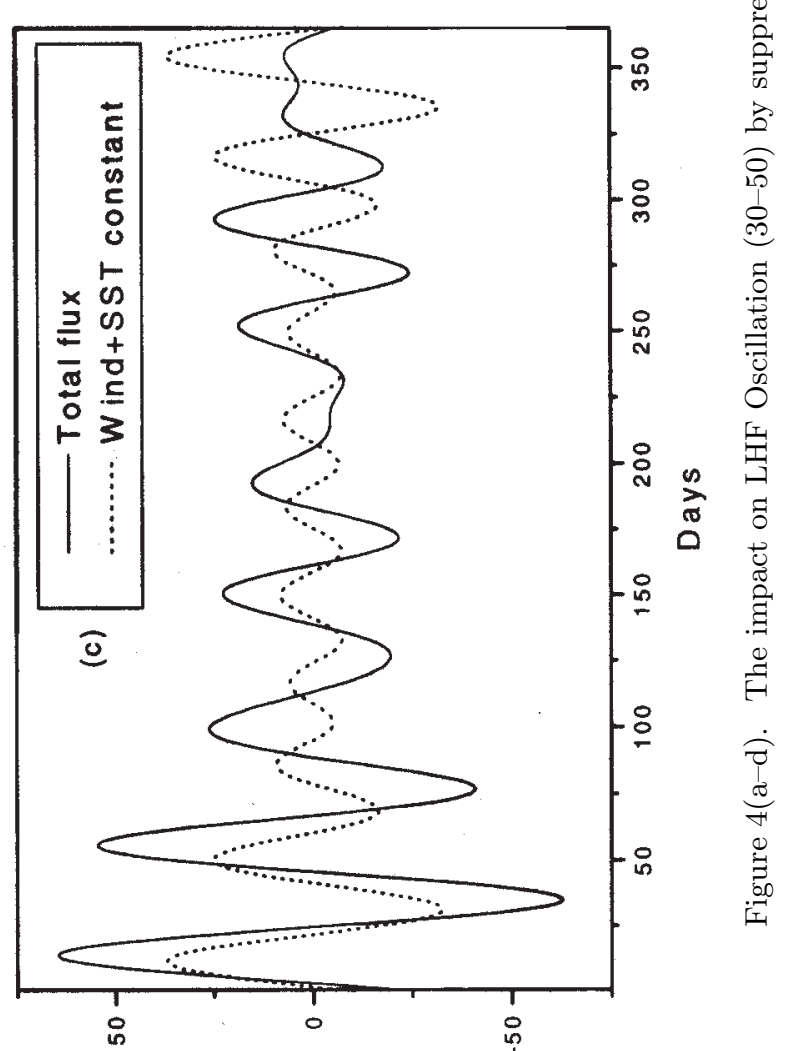

(ट. $w / M)$ әpn!!!d $u \forall$ 





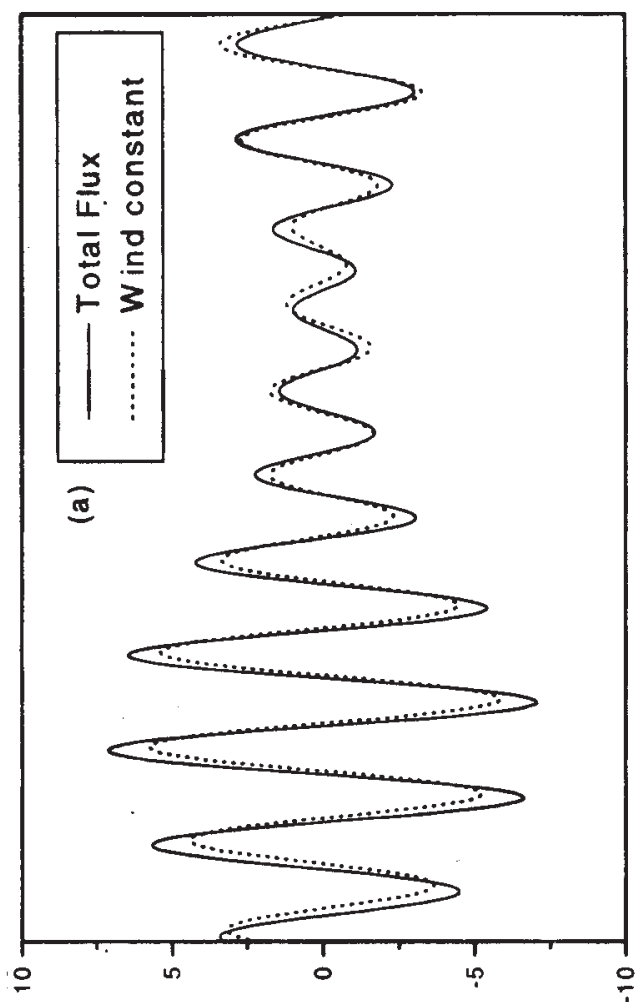

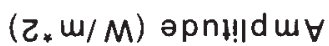

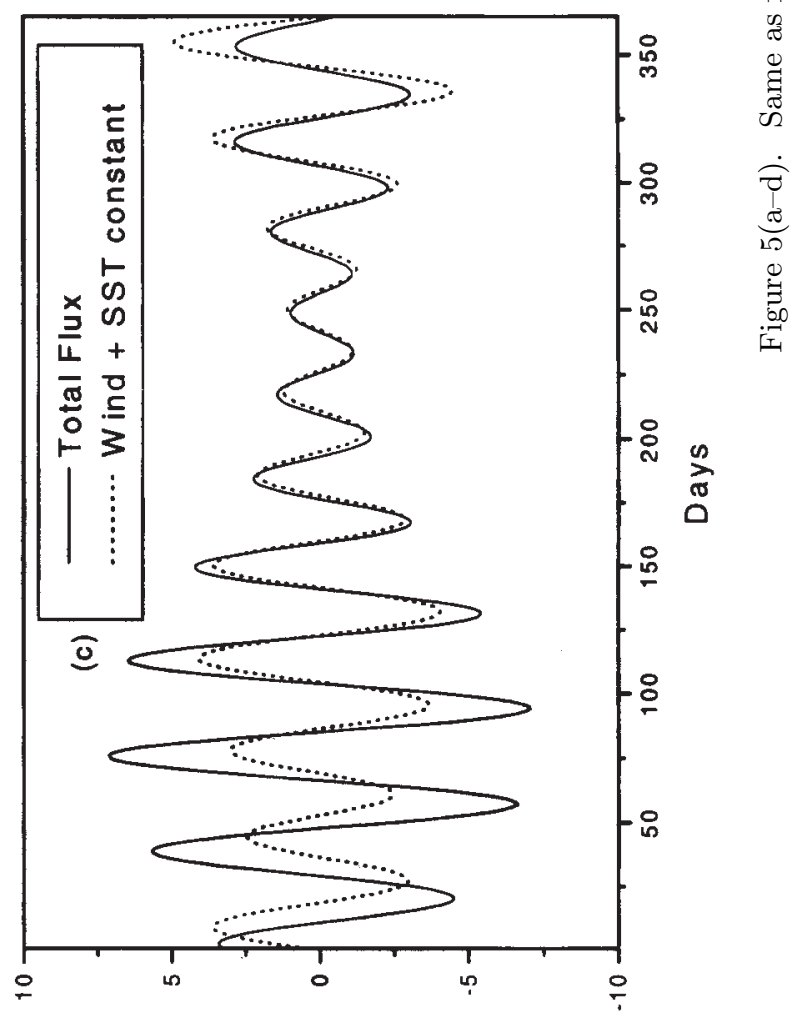

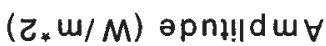



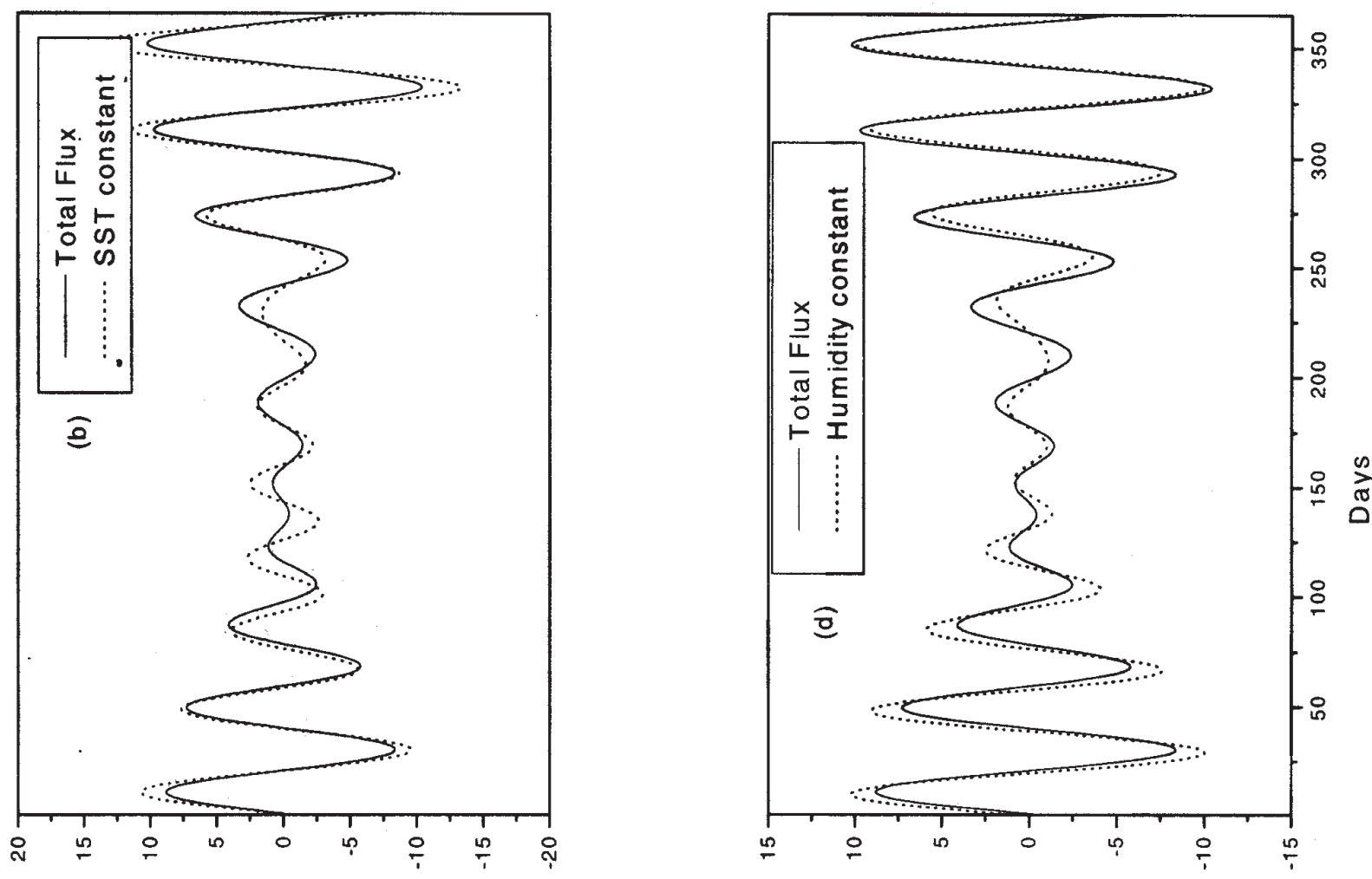

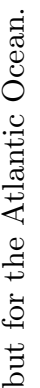

oscillations on time scale of $30-50$ days seem to force SST oscillation on this time scale over the Indian Ocean. Over the Atlantic and Pacific Oceans this inverse relation between wind and SST is not found. The amplitude of SST oscillation over the Indian Ocean is of the order of $0.2^{\circ} \mathrm{C}$ while that of wind is almost $1 \mathrm{~m} / \mathrm{s}$. The amplitude of LHF oscillation on this time scale is about $60 \mathrm{watt} / \mathrm{m}^{2}$ (figure 4) while that of surface specific humidity is of the order of $0.3 \mathrm{~g} / \mathrm{kg}$ over the Indian Ocean. Over the Pacific Ocean the amplitude of oscillation in these variables are of the order of $10 \mathrm{watt} / \mathrm{m}^{2}$ (figure 5 ), $1 \mathrm{~m} / \mathrm{s}, 0.12^{\circ} \mathrm{C}$ and $0.3 \mathrm{~g} / \mathrm{kg}$ respectively. Similarly over the Atlantic Ocean the amplitude of these oscillations are about $8 \mathrm{watt} / \mathrm{m}^{2}$ (figure 6 ), $0.2 \mathrm{~m} / \mathrm{s}, 0.5^{\circ} \mathrm{C}$ and $0.7 \mathrm{~g} / \mathrm{kg}$ respectively.

Similar analyses have been done for the Indian Ocean for the years 1987 and 1988 which were deficient and excess Indian summer monsoon rainfall years. The amplitude of the oscillations during 1987 (deficient year) was $45 \mathrm{watts} / \mathrm{m}^{2}$, whereas, for 1988 (excess rainfall year) it was 40 watts $/ \mathrm{m}^{2}$ during the summer monsoon season. The sensitivity of latent heat flux to the suppression of oscillation in one or another variable over the three oceans is illustrated in figure $4(\mathrm{a}-\mathrm{d})-6(\mathrm{a}-\mathrm{d})$. In all the figures the solid line denotes the total latent heat flux on the time scale of 30-50 days. The dotted lines show the results after suppressing the oscillation in the wind, SST and humidity respectively. For Indian Ocean, figure 4(a) results when the wind oscillations are suppressed, figure 4(b) results when the SST oscillations are suppressed, figure 4(c) when oscillations in both (wind and SST) are suppressed and figure 4(d) when surface specific humidity oscillations are suppressed. Figure $5\left(\mathrm{a}^{-}\right.$ d) shows the results for the Pacific Ocean while figure $6(\mathrm{a}-\mathrm{d})$ shows the results for the Atlantic Ocean. It is apparent from these figures that SST has a minor role on latent heat fluxes oscillation on this time scale of 30-50 days. The major sensitivity to these oscillations come from the surface wind and the moisture. The wind and moisture impact is stronger than SST over all the oceans.

\section{Conclusions}

Since the pioneering study of Madden and Julian (1971, 1972) several major observational studies have clarified the three dimensional structure of atmosphere oscillations on this time scale of MJO (Yasunari 1979; Murakami et al 1984). Basic questions regarding the mechanism for these oscillations have not been fully understood. Lim and Chang (1987) propose a Kelvin Wave-CISK mechanism for excitation of eastward propagating tran- sient motion on this time scale. Eastward propagating wave can perhaps be driven by cumulus convection on this time scale, which requires steady supply of moisture from the ocean. We have noted that on this time scale (30-50 days) the latent heat flux is around 8 to $60 \mathrm{watt} / \mathrm{m}^{2}$ from ocean to atmosphere, whereas total transfer of latent heat flux is around 130 to $170 \mathrm{watt} / \mathrm{m}^{2}$. Our study indicates that the oscillation of the wind and moisture is dominant over the Indian and Pacific Oceans on this time scale of ocean atmosphere coupling. Over the Atlantic Ocean the moisture is dominant compared to wind. The contribution of SST oscillation on this time scale is very small. The most pronounced oscillation in moisture and wind occur over the Indian Ocean.

\section{Acknowledgements}

Authors would like to thank the COADS Data Archives Centre for providing the in situ surface meteorological data. The NCEP data were made in useable format with the help of Pradeep Kumar Thapliyal and is gratefully acknowledged. Authors are also thankful to Dr. M S Narayanan, Dr. P K Pal and Dr. C M Kishtawal for fruitful discussions.

\section{References}

Cadet D 1983 The monsoon over Indian Ocean during summer 1975, part II: Break and active monsoon; Mon. Weather Rev. 111 95-108

Emanuel K A 1987 An air-sea interaction model of the intraseasonal oscillation in the tropics; J. Atmos. Sci. 44 2324-2340

Hendon H H and Salby M L 1994 The life cycle of Madden Julian oscillation; J. Atmos. Sci. 51 2225-2237

Krishnamurti T N and Bhalme H H 1976 Oscillation of monsoon system, part 1: Observational aspects; J. Atmos. Sci. 33 1937-1954

Knutson T R and Weinckmann K M, 1987 30-60 day atmospheric oscillations: composite life cycles of convection and circulation anomalies; Mon. Weather Rev. 115 1407-1436

Kumar K and Jain A R 1992 A study of atmospheric waves of 30-50 day period in zonal wind over near equatorial station Thumba; Indian J. Radio Space Physics 21 42-46

Lim H and Chang C P 1987 Dynamics of midlatitude - tropical interactions during winter monsoon, monsoon meteorology (ed) C P Chang and T N Krishnamurti (Oxford University Press)

Lau K M and Peng L 1987 Origin of low frequency oscillations in the tropical atmosphere, part 1: Basic theory; $J$. Atmos. Sci. 44 950-972

Madden R A and Julian P R 1971 Detection of 40-50 day oscillation in zonal wind in the tropical Pacific; J. Atmos. Sci. 28 702-708

Madden R A and Julian P R 1972 Description of globalscale circulations cells in the tropics with a 40-50 day period; J. Atmos. Sci. 29 1109-1123 
Murakami M 1984 Analysis of deep convectivity over the western Pacific and south east Asia part II; J. Met. Soc. Japan 62 88-108

Murakami M 1979 Large scale aspects of deep activity over GATE area. Mon. Weather Rev. 107 9941013

Reynolds R W and Smith T M 1994 Improved global sea surface temperature analyses using optimum interpolation; J. Climate 7 929-948
Stevens D 1983 On symmetric stability and instability of zonal mean flow near the equator; J. Atmos. Sci. $40882-$ 902

Sikka D R and Gadgil S 1983 On maximum cloud zone and the ITCZ over Indian longitude during the southwest monsoon; Mon. Weather Rev. 108 1840-1853

Yasunari T 1979 Cloudiness fluctuations associated with the northern hemisphere summer monsoon; J. Meteor. Soc, Japan 57 227-242 